\title{
Rural Women's Access to Credit and Extension: A Strategy for Change
}

\author{
SHAHNAZ KAZI and BILQUEES RAZA
}

\section{INTRODUCTION}

Although still 'invisible' to policy-makers, women's involvement in agricultural and livestock production is empirically established through national surveys and intensive studies. The labour force participation rates for rural women in 1990-91 varied ranged between 57 percent (Agricultural Census) and 43 percent (Pakistan Integrated Household Survey). Evidence from micro studies also shows that women are active participants in the farm and livestock sectors [Freedman and Wai (1988); Masood (1988); Ali et al. (1976); Haque (1986); Khan and Bilquees (1976)].

While rural women's contribution to agricultural and livestock production is well-documented, they have little or no access to productive inputs to enhance their economic participation in these sectors. Evidence based on national level data indicates that women's participation in agricultural activities is constrained by the lack of land and other assets [Sathar and Desai (1994)]. Contrary to the general view, women belonging to households that own land or other assets have a higher labour force participation rate than landless women. While landless women are more likely to work as agricultural labourers, however, the demand for wage employment is seasonal, limited to a few activities and certain regions, and their lack of assets to work with excludes any possibility of self-employment. Findings of village level research indicate a wide gap between the technology used by rural women and the more efficient practices in livestock production, which is attributed to their lack of contact with extension services and to their lack of resources to adopt more efficient methods of livestock care [Haque (1986)].

There is clearly a strong need to raise women's knowledge of efficient management practices and to facilitate their access to necessary resources. These interventions are essential not only because of their likely beneficial effect on women's economic autonomy, but also to meet the sector's objective of raising farm and livestock production. A programme aimed at raising production through delivery of extension services and credit cannot be effective if it fails to provide the inputs to

Shahnaz Kazi is Chief of Research and Bilquees Raza is Staff Economist at the Pakistan Institute of Development Economics, Islamabad. 
active participants in the sectors. Various evaluations have clearly indicated that when males are targeted by extension programmes, the requisite information is seldom transferred to women; and even if there is some exchange, it may lose in accuracy through reliance on communication through a third person [MFSP (1989); MFSP/AHITI (1992)].

Government policies till recently have not addressed the production needs of women with any degree of seriousness. The main objective of the present study is to critically review the performance of the few credit and extension programmes which have been targeted at rural women, with a view to devising more effective strategies to guide future interventions in the area. The focus of the paper is mainly on government-sponsored schemes.

\section{CREDIT}

\section{Access of Rural Women to Credit}

The poor strata in general are disadvantaged in terms of access to credit. Women's access is further constrained by limited mobility, illiteracy and, most importantly, the lack of assets for collateral, since women rarely have legal ownership of land. There have been some limited efforts to increase women's access to financial facilities through formal institutions, which are reviewed in this section. These include some initiatives by the Agricultural Development Bank of Pakistan (ADBP), the Cooperatives Departments, and the First Women's Bank Ltd. (FWBL).

\section{The First Women's Bank Ltd. (FWBL)}

The FWBL, established in 1989, is the only formal financial institution set up to cater to the needs of women, and currently has 29 branches concentrated in urban and semi-urban areas. The bank, which is entirely staffed and managed by women, operates on commercial banking principles, offering all the usual facilities including foreign exchange transactions. However, for smaller loans of Rs 25000 or less, a system of group guarantees or 2 personal guarantees is substituted for asset-based collateral requirements.

While the bank has collaborated with some NGOs to reach poor women, and has instituted a system of group guarantees, the extent of these attempts to reach poor women has not yet been fully assessed. However, the overall orientation of the bank is clearly not aimed at a clientele of low-income women in the urban and rural areas. Given the lack of any field staff, improving access to poor borrowers has not been an important objective. Of the total loans sanctioned so far, 95 percent have gone to urban areas and, from all indications, to middle-class women entrepreneurs [Kamal (1994)]. However, the Bank plans to extend its coverage of rural women by channellising credit facilities through existing banks, cooperatives, and NGOs. 
The approach of the bank underlines the need to qualify any policy designed for women in terms of clearly-defined target groups. There are wide variations in access to resources across women from different socio-economic groups. While women from the better-off sections of society are part of the mainstream, and in most cases have access to modern sector institutions, the rationale of setting up a special women's institutions should be to target women who are usually excluded from the services provided through regular channels. Although financial viability is an important consideration, it does not necessarily follow that it should override the central objective of such ventures. The experience of other South Asian countries has shown that given sound project design and implementation policy, there need not be a conflict between financial sustainability and improved access to the poor.

\section{The Agricultural Development Bank of Pakistan (ADBP)}

The ADBP is the major source of agricultural credit and loans to cottage industries in rural areas. The bank has initiated two schemes where special provisions were made to extend the outreach to poor farmers and to rural women. The Gujranwala Agricultural Development Project (GADP), initiated in 1985, introduced the system of the Couple Mobile Credit Officers (CMCOs) to extend outreach to women. The team consisted of a male MCO and his wife, the female MCO, who were to promote, disburse, supervise, and recover loans. The collateral requirements, however, remained quite stringent and required either 2 personal guarantees or property. Less than 7 percent of the total loans sanctioned under this scheme till 1992 have gone to female applicants [Kamal (1994)].

More recently, the ADBP has launched the Agricultural Credit Programme (ACP), which is also targeted at the landless rural poor and small farmers. The programme has experimented with various pilot schemes to deliver credit to women through using female fields staff, as well as trying different forms of collateral. The Couple Mobile Credit Officers scheme is supported by a female village assistant to identify potential clients. The design of this project also includes a system of group guarantees or the use of gold as substitutes for land collateral. The use of NGOs as intermediaries is also planned. Despite incorporating all the right principles in the planning stage, the implementation has been problematic and the programme launched in July 1992 has yet to make any significant progress. The hindrances identified by bank officials in implementing the programme include the high operational costs, problems in recovery, and the limited number of skilled women in the rural area. These restrict the bank's programme of loan diversification. The lack of assets or property by poor women to serve as collateral and their inability to find a personal guarantor were viewed as the most important impediments. After more than 18 months of operation, only 56 women had been given loans under the scheme [UNDP/UNIFEM/SUNGI (1994)]. 
The ACP has been grafted onto a system which has a tradition of large loans and land-based collateral and little or no experience with innovative lending procedures tailored to the needs of the poor. A major shift in the approach requires, at a minimum, a clear commitment at the top levels of management as well as appropriate training of the staff in innovative procedures to ensure effective reorientation of the delivery system. At present, these pre-requisites for launching a major credit initiative are lacking.

\section{Cooperative Banks and Societies}

The cooperative structure in Pakistan is essentially oriented to the problems of rural indebtedness through supply of credit. Out of a total of 61,000 cooperative societies in 1990, only 952 comprised women's cooperatives, and of these the overwhelming majority (867) were located in the Punjab. A detailed investigation of special women's cooperatives in the Punjab indicates that they comprise mainly of thrift societies and some industrial societies [Kazi (1992)]. The main objective of the thrift societies is to promote savings and to introduce women to normal banking facilities, but this does not extend to the provision of loans in contrast to the credit orientation of other cooperative societies. The industrial societies are supposedly producer cooperatives although, in fact, they are welfare-oriented skill training programmes for women. The members are not the workers themselves, but the wellto-do women in the community who are basically motivated by charitable considerations. The functioning of these industrial societies is along the lines of welfare organisations, rather than that of genuine producer cooperatives, as women spend their days sewing and embroidering products for which there is no real market and are subsidised by donations from well-meaning women. At present, special women's cooperatives, given their limited scope of activities, are excluded from facilities available to the cooperatives in general, such as credit and training provided through the Federal Bank for Cooperatives and the Cooperative Departments.

The Seventh Plan had placed special emphasis on the promotion of women's cooperatives especially in the fields of credit, handicrafts, supply of agricultural inputs, and marketing. In response to these guidelines, the Ministry of Women's Development initiated some schemes in 1988 with the objective of providing production credit for rural women through cooperatives.

However, in most cases, these schemes were not implemented. The major obstacle to initiating these programmes was the inability of the respective provincial department to work out a system for the recovery of loans from women who were unable to fulfil the legal requirements of providing security against the loan [Government of Pakistan (1990)]. In Sindh, there was a move to shift the focus of the project from the provision of production loans to a scheme for imparting training to women. The failure to implement the credit schemes, which had been officially 
sanctioned and for which the funds had been released, is an indication of the low priority assigned to these projects and the lack of motivation to get around certain constraints which have been successfully handled in credit schemes for women in other South Asian countries as well as in some NGO initiatives within the country. Further, the last case, whereby the credit schemes are expected to be replaced by special skill training programmes for women, underlines a problem not unique to Pakistan: the case pertains to the project design based on women's productive roles transformed, at the implementation stage, into a typical welfare-oriented women's project.

\section{Policies to Improve Rural Women's Access to Credit}

The implementation problems experienced in the recent ACP programme of the ADBP, the limited outreach of the First Women's Bank, and the total exclusion of women from credit provided by the Cooperative System are in direct contrast to the experience of South Asian countries with common socio-cultural settings, indicating that well-designed and well-implemented financial services can be an effective way to reach poor women.

Features of successful credit programmes include commercial interest rates, a strong emphasis on savings, a system of group guarantees, the use of the NGOs as intermediaries or, alternatively, an extensive network of field staff. Training of the staff in innovative credit approaches is needed, but most importantly, a commitment at the highest levels of management has been essential for the success of such efforts. Most of these principles are found in the credit schemes of the Agha Khan Rural Support Programme and the Balochistan Rural Support Programme, which extend loans to rural women while maintaining financial discipline.

Financial institutions like the First Women's Bank Ltd., the Cooperative Banks, and the Agricultural Development Bank need to experiment with delivery mechanisms based on an assessment of the credit needs of small women borrowers particularly in the rural areas. Recruitment of female field staff is an essential component of a programme to reach women in the context of Pakistan, where cultural constraints are rigid and the possibility of social intermediation, with a few exceptions, is limited due to the sparse distribution of development-oriented, community-based NGOs. Training of the staff in innovative approaches is also a prerequisite for introducing such schemes.

The Cooperatives Department has shown extreme rigidity in deviating from its standard procedures, which was reflected in its failure to implement the MWDsponsored credit projects for women. At a minimum, the Department should ensure that women's cooperatives have access to public resources in the form of credit and training through the system which are currently denied to them, even as they are 
available to most other societies. The Department already has field staff. However, the female staff is currently oriented to the welfare content of the programme and will need to be trained in the provision of credit services.

\section{EXTENSION AND TRAINING}

Most projects for the provision of skill training and extension services have, by and large, not been effective, since in many cases they were not related to women's requirements in the area.

\section{Training Programmes}

The Ministry of Women's Development has financed a large number of multipurpose training centres targeted at low-income women in rural and urban areas. These centres were expected to provide adult education courses as well as training in sewing, knitting, and embroidery. A large number of such units were set up under various schemes implemented by the provincial Departments of Social Welfare, Education, etc. In the province of Sindh alone, there were 520 such centres, of which 415 were known as Women's Centres and 105 as Multi-purpose Women['s] Welfare Centres. Most of these projects have failed due to poor response from the intended beneficiaries since the training in "feminine" skills had little relevance to women's main source of livelihood in the agriculture and livestock sectors [Government of Pakistan (1990)].

\section{Agricultural and Livestock Extension Programmes}

Some potentially useful schemes to recruit and train female staff to deliver extension to women farmers have experienced problems because the project design has not adequately addressed the issue of women's mobility. There was a strong need for such a project to improve access of women to extension services, since the current services are entirely staffed by males and are oriented to male agriculturists. The programme failed to make an impact because the issue of women's mobility was not adequately addressed in the design. Field assistants who were recruited from urban areas were reluctant to be posted to rural pilot centres.

The Livestock Departments of Punjab and the NWFP have recently initiated a scheme of hiring female extension staff to disseminate knowledge on improved technology directly to women livestock-holders. While it is too early to assess the impact of these programmes, difficulties related to the hiring and retention of women extension workers have already emerged as a major obstacle to the implementation of the scheme in the Punjab. The female staff were recruited at a higher level, equivalent to a Grade 17 officer, and were required to have a degree in Veterinary Science, which was subsequently relaxed to a Master's in Rural Sociology. 
The entry requirements did not just limit the number of applicants; the eligible candidates were mainly urban women who were not willing to be posted away from the major cities. The NWFP programme is based on a more viable approach to the hiring of the female staff, who are appointed at a lower level of Grade 11. The educational requirement is matriculation, and strong preference is given to girls with a rural background, particularly in the regions of the area of project operation. Also, the staff was given intensive field-oriented training for a period of two-and-a-half years.

While the NWFP recruitment and training policy is based on sounder principles, a major shortcoming which is common to both the programmes is the lack of technical support and supervision for the female extension programme. Further, the staff is hired on a contract basis, with no assurance that the posts will be regularised in the future.

One of the few successful efforts to improve access of rural women to extension services was the programme on fruit and vegetable production and preservation, which was implemented by the Fruit and Vegetable Board in the NWFP. Under this project, female field assistants were recruited and placed in 48 centres. While the evaluation of the programme was very favourable, the sustainability of the project is in question since the NWFP government is not willing to regularise the posts of female field assistants [Government of Pakistan (1990)]. This problem is common to a number of WID components of projects which continue to be financed by the Ministry of Women's Development. The problem mainly stems from the fact that provincial governments are reluctant to expend their limited resources on what is rarely seen as productive expenditure.

The lessons learnt from past experiences have underlined the need to address some critical issues in the design and implementation of extension programmes for women farmers and livestock-holders. These include the importance of mobility considerations, the need to train local women, the inflexibility of various departments in integrating women in their activities, the relevance of the content of training to women's needs, and the problems of sustainability of women's projects.

\section{CONCLUSIONS}

The findings which emerge from the review of some efforts to provide credit and extension services to rural women serve as the basis of defining a broader strategy to improve access of rural women to productive resources. The key elements of such a strategy are outlined below.

1. An extensive network of female field-workers is essential to delivering services to rural women. Recruitment of local women as service-providers is increasingly emerging as an important pre-requisite for successfully addressing the problems of retaining female staff in rural postings, as well 
as being more conducive to communication with the largely illiterate rural clients, such communication being the primary function of a field-worker. The policy of hiring of local women would require, in some areas of acute shortage, a relaxation of the recruitment criteria related to qualifications and age. These principles have largely been accepted with respect to women workers in the social sectors, and are reflected in lowered qualification and entry requirements, where necessary, for teachers and more recently for the village-based health and population workers scheme. It is necessary to apply the same principles to female providers of productive resources.

2. The quality of the services provided, whether it is credit or extension messages, will be critically dependent on the training, technical support, and supervision of the female paraprofessionals. Particularly, the deployment of a cadre of less qualified workers needs to be closely backed up by the requisite professional support.

3. Recent experience in various South Asian countries and, on a much smaller scale, in Pakistan has underlined the importance of organising women's groups as an effective means of distribution of inputs, particularly credit. This approach, however, should be used with caution particularly in settings where there are wide disparities in class and economic status of the community. In such situations, which are quite commonly found in various rural areas of Pakistan, past experience indicates that organisations tend to be controlled by the èlite who also benefit disproportionately from their resources. Relatively homogeneous groups, not marked by sharp differences in economic or social status, are an important precondition for the successful working of these organisations.

4. NGOs can be important catalysts for organising women, although at present their coverage in rural areas is quite limited. In the areas where they exist, there is a need to promote greater collaboration between the NGOs and the line departments as well as financial institutions. NGOs are in a better position to assess the needs of the community and to generate the demand for public facilities, and they are able to advise line agencies on designing more effective delivery mechanisms.

5. At present, due to the lack of any significant government interventions designed to cater to women's productive needs in terms of credit, extension services, and formation of women's organisations, there is very limited knowledge of what works in these areas across different settings. In this context, it may be useful to experiment through appropriate pilots to identify designs of effective delivery mechanisms which may not be cost- 
effective in the short run but can serve as the basis of a larger and more effective programme at a later stage.

6. In general, integrating women in institutions such as the Agriculture, Livestock, and Cooperatives Department, and the Agricultural Development Bank of Pakistan (ADBP), which at present typically bypass women and exhibit a strong bias in favour of large farmers, is a formidable task. The female staff is likely to face problems in inter-departmental coordination, and still other problems related to their integration in a maledominated system. There is a danger that the delivery of services to women farmers will be viewed as solely the responsibility of the female staff, resulting in the isolation of the WID component from the mainstream programme. As in other such situations, it is necessary to get the message across to the staff at all levels that the delivery of services to female farmers is a priority for the financial or extension system as a whole. Effective reorientation of the delivery mechanisms of these departments to the needs and requirements of women clients will, at a minimum, require raising awareness of the staff, both male and female, on women's roles in these sectors, as well as training them in new and innovative approaches to the delivery of credit and extension which address the constraints of female clients. Most importantly, it would require support for the programme from senior officials.

Implementation will be greatly facilitated by a strong commitment to women's development by national leaders. A clear mandate is required from the highest levels of decision-making to reorientate the priorities of the bureaucracy. While the government has taken steps in this direction by strongly supporting the Social Action Programme, its commitment to the incorporation of women's concerns in the mainstream economic programmes has yet to be demonstrated.

\section{REFERENCES}

Ali, M., T. Q. Azam, and I. Saeed (1976) The Invisible Farmer: A Profile of Pakistani Rural Women. Pakistan Manpower Review 11:1.

Freedman, J., and L. Wai (1988) Gender and Development in Barani Areas of Pakistan. Agriculture Canada. (Report.)

Haque, H. (1986) Role of Women in Livestock Production and Management Decisions. Unpublished paper, presented at the workshop on Some Aspects of Barani Area Development, Islamabad.

Kamal, S. (1994) Inequalities in Women's Access to and Participation in the Definition of Economic Structures and Policies and the Productive Process Itself. Unpublished paper. 
Kazi, S. (1992) Gender Integration in Cooperatives: Pakistan. New Delhi: International Cooperative Alliance.

Khan, S. A., and F. Bilquees (1976) The Attitudes, Environment, and Activities of Rural Women: A Case Study of Jhok Sayal. Islamabad: Pakistan Institute of Development Economics.

Masood, F. (1988) Women in Traditional Irrigated Farming Systems. In Rural Women in Pakistan's Farming System's Research. Islamabad: Pakistan Agricultural Research Council.

MFSP (1989) Impact Assessment of Malakand Social Forestry Project. Peshawar: Malakand Social Forestry Project.

MFSP/AHITI (1992) Rapid Rural Appraisal of Selected Areas in Malakand. Peshawar: Malakand Social Forestry Project/Animal Husbandry Training Institute.

Pakistan, Government of (1990) Evaluation of the Ministry of Women's Development Projects in the Provinces. Islamabad: Planning and Development Division.

Sathar, Z., and S. Desai (1994) Work Patterns in Rural Pakistan: Intersection between Gender, Family, and Class. Unpublished paper, present at the Annual Meeting of the Population Association of America, Miami.

UNDP/UNIFEM/SUNGI (1994) Report of the Workshop on Access to Credit for Rural Women in Pakistan. Islamabad: UNDP/UNIFEM/SUNGI. 


\section{Comments}

The authors make a commendable effort to discuss the existing scenario, detailing the areas where women are involved in farm and off-farm activities along with the status and the reporting of those activities in national data.

Reference is also made to micro level studies for information and data.

The paper lays out the sources and institutions that women can access for credit, such as the First Women's Bank Ltd., the Agricultural Development Bank of Pakistan, and the Cooperative Banks and Societies. There is a good analysis of these institutions vis-à-vis their role and constraints in providing credit to women.

This is followed by a review of policies to improve rural women's access to credit. This is an important section and the paper highlights the features of a successful credit programme that include, among others, the use of "commercial interest rates, savings, a system of group guarantees, the use of intermediaries or field staff to reach the target groups, and the training of staff to undertake innovative credit approaches". However, the most important and critical factor is the need for "commitment at the highest level of management".

The following part of the paper dwells on the FWB, ADBP, the Cooperative Banks, and the existing status of staff and training components of these institutions, highlighting the reasons for their failure in being able to bring women within their credit ambit. Next, the extension and training programmes in vogue for women are dealt with. The final section deals with the findings that emerge and then lays out a strategy. The strategy focuses on seven major points, as follows.

1. The need for an extensive network of female field-workers, locally recruited preferably, to reach the female clientele, and the relaxation of recruitment criteria related to qualification and age where women with the requisite qualifications are not available.

2. The need for training, technical support, and supervision of female paraprofessionals to ensure quality of service.

3. Use of women's groups. Here the paper suggests that some pre-conditions are to be met. These are that the area should have a "relatively homogeneous group, not marked by sharp differences in economic or social status". In the absence of this, the organisations tend to be under the control of the èlite who are also the major beneficiaries.

4. Use of NGOs and the need for closer collaboration between the NGOs and line departments.

5. Pilot projects are to provide information of the workability of designs and effective delivery mechanisms. 
6. We need to ensure that in the process of integrating women in institutions, such as the Agricultural, Livestock, and Cooperative departments and the Agricultural Development Bank of Pakistan, the females should not be left with just the responsibility of catering to the needs of women. The delivery of services to female farmers is a priority for the financial or extension system as a whole. There is also a need for support from senior staff to integrate women and their needs into the programme.

7. There should be a strong commitment to women's development by national leaders, with a mandate from the highest levels of decisionmaking to reorientate the priorities of the bureaucracy.

The paper does a good job in terms of documentation of information and analysis. However, a few points may be considered in laying out a strategy for change as envisaged. Perhaps the last point in the paper should be the starting-point of the strategy and be considered as a pre-requisite. This deals with a genuine commitment from the highest level to mainstream women into the development process, specifically focusing on their needs and constraints. There are two major areas of concern: (1) structural and (2) budgetary. In the first case, the first problem is the lack of visibility of women in most departments and institutions due to the very small number of women employed in these departments/institutions, and the resulting lack of understanding of women's issues and concerns in the planning and implementation of programmes for women. The problem is even more acute for rural areas where individual perceptions guide the planning decisions. The budgetary aspect becomes important particularly in the case of externally funded projects where the recurrent expenditure needs to be taken over into the Annual Development Programme and decisions have to be made despite budgetary constraint. In this situation, the sustainability of the programme is threatened and, more importantly, the cadre of trained women becomes jobless. The situation becomes worse since there is already a lack of trained women to carry on the government's development programme.

The second pre-requisite is that any programme or project planned for women must target the socio-economic group that it is planned for, and the programme be designed only after a needs assessment has been undertaken.

Two different scenarios may be envisioned.

1. If it is only a programme for credit supply with no other facilities offered, such as training or extension service, then the target group will have to be the one that is already involved in the activity for which credit supply is being planned. An important consideration will be the terms and conditions on which credit is being offered. This includes the form of the collateral required, the productivity of the loan, and the absorptive capacity of the client. Women generally tend to be risk-averse. The 
training and personality of the field-worker sent to contact and identify these women-clients will be critical for the success of the programme.

2. Development projects that provide training or skill development with the ultimate aim of enabling women to generate income will need to provide, or act as a catalyst for provision of, credit and market information to the women. The design of the project should provide for intermediaries such as NGOs, VOs, women's groups or social workers to undertake this function.

Thus, the credit needs of women should be addressed through a multi-faceted programme, where policies play a major role in creating an enabling environment. At the same time, the low social indicators and social constraints that women face and which act as obstacles will have to be overcome through training and extension services to target the identified needs of women.

Centre for Applied Economic Studies,

S. Zia Al-Jalaly

University of Peshawar,

Peshawar. 